\title{
Strict glycemic control reduces EuroSCORE expected mortality in diabetic patients undergoing myocardial revascularization
}

Cosimo D'Alessandro, MD, ${ }^{a}$ Pascal Leprince, MD, PhD, ${ }^{\text {a }}$ Jean Louis Golmard, PhD, ${ }^{c}$ Alexandre Ouattara, MD, PhD, Stéphane Aubert, MD, ${ }^{a}$ Alain Pavie, MD, ${ }^{a}$ Iradj Gandjbakhch, MD, ${ }^{a}$ and Nicolas Bonnet, MD $^{\mathrm{a}}$

See related articles in Seminars in Thoracic and Cardiovascular Surgery, Vol 18(4), Winter 2006: Diabetes, Hyperglycemia, and the Cardiac Surgery Patient. Available on line at ScienceDirect.com and SemThorCardiovascSurg.com.
From the Institute of Cardiology, Division of Thoracic and Cardiovascular Surgery, ${ }^{\text {a }}$ Department of Anesthesia and Critical Care, ${ }^{\mathrm{b}}$ and Department of Biostatistics, ${ }^{\mathrm{c}}$ Centre Hospitalier Universitaire Pitié-Salpêtrière, Assistance Publique-Hôpitaux de Paris, Université Pierre et Marie Curie-Paris, Paris, France.

Received for publication July 27, 2006; revisions received Feb 7, 2007; accepted for publication Feb 19, 2007.

Address for reprints: Cosimo D'Alessandro, MD, Division of Thoracic and Cardiovascular Surgery, Hôpital La Pitié-Salpêtrière, 47-83 Boulevard de l'Hôpital, 75651 Paris Cedex 13, France (E-mail: cosimodalessandro@ wanadoo.fr).

J Thorac Cardiovasc Surg 2007;134:29-37

$0022-5223 / \$ 32.00$

Copyright $(92007$ by The American Association for Thoracic Surgery

doi:10.1016/j.jtcvs.2007.02.028
Objective: We sought to evaluate the effect of a strict glycemic control protocol on a series of diabetic patients undergoing surgical myocardial revascularization.

Methods: Between January 2003 and June 2004, 300 diabetic patients undergoing myocardial revascularization received a local protocol of insulin administration (protocol, group P). Patients were divided into 2 risk classes, according to their additive EuroSCORE value: low-moderate risk $(0-4)$ and moderate-high risk $(>4)$. The logistic EuroSCORE algorithm was used to calculate the expected probability of death. A control group was selected, including a series of 300 consecutive diabetic patients (no protocol group, group NP) who underwent coronary artery bypass grafting between March 2001 and September 2002, just before the introduction of the protocol. A propensity analysis was performed to control for selection bias.

Results: Both groups showed similar EuroSCORE risk profiles: mean additive and logistic EuroSCORE values were 4.16 and 4.29 in group P versus 3.93 and 3.91 in group NP. Observed and expected mortalities of group P were $0.6 \%$ versus $1.8 \%$ (low-moderate risk), $2.5 \%$ versus $8.0 \%$ (moderate-high risk, $P=.03$ ), and $1.3 \%$ versus $4.3 \%$ (entire group, $P=.01$ ). Observed and expected mortalities of group NP were $1.6 \%$ versus $1.9 \%$ (low-moderate risk), $8.3 \%$ versus $7.5 \%$ (moderate-high risk), and $4.0 \%$ versus $3.9 \%$ (entire group). Logistic regression confirmed observed mortality in group P to be significantly lower than the expected logistic EuroSCORE mortality. After risk adjustment, the protocol allowed us to reduce the mortality odds by $72 \%$ (odds ratio, 0.282; 95\% confidence interval, 0.092-0.859; $P<.03$ ). Subgroup analysis for moderate- to high-risk patients showed the protocol to improve mortality (odds ratio, $0.24 ; P<.05$ ), whereas no significant improvement was found in low- to moderate-risk patients. Addition of the propensity score to the multivariable analysis did not significantly displace $P$ values and odds ratios. Sensitivity analysis of patients who underwent coronary artery bypass grafting without additional procedures showed the protocol to maintain its protective effect (odds ratio, $0.15 ; P<.05$ ).

Conclusion: Optimal glucose control highly reduces EuroSCORE expected mortality in diabetic patients undergoing myocardial revascularization, especially in moderate- to high-risk patients.

$\mathrm{W}$ orldwide, there are more than 150 million adults estimated to have diabetes mellitus (DM), and that number is expected to increase. ${ }^{1}$ Since the first reports from the Framingham study, diabetes has been recognized to be an independent risk factor for the development of coronary artery disease, ${ }^{2}$ which represents the most common cause of death in diabetic patients. ${ }^{1}$ Diabetic patients represent nearly $25 \%$ of revascularization procedures, coronary 


\author{
Abbreviations and Acronyms \\ $\mathrm{BGL}=$ blood glycemic level \\ $\mathrm{CABG}=$ coronary artery bypass grafting \\ $\mathrm{COPD}=$ chronic obstructive pulmonary disease \\ $\mathrm{DM}=$ diabetes mellitus \\ ICU = intensive care unit \\ ITA $=$ internal thoracic artery \\ LVEF = left ventricular ejection fraction \\ $\mathrm{O} / \mathrm{E}=$ observed/expected ratio \\ $\mathrm{OR}=$ odds ratio
}

artery bypass grafting (CABG) operations, or percutaneous transluminal coronary angioplasty, and they do worse after either type of chosen revascularization compared with nondiabetic patients. ${ }^{3}$ Although diabetic patients frequently have concomitant risk factors, DM has been proved to be an independent risk predictor of early ${ }^{4-6}$ and late ${ }^{6,7}$ mortality after CABG. In the Diabetes mellitus Insulin-Glucose infusion in Acute Myocardial Infarction (DIGAMI) study Malmberg and colleagues ${ }^{8}$ reported that glycemic control by insulin infusions provided better long-term survival in diabetic patients having experienced myocardial infarction (MI). Other works suggested that strict glycemic control can improve outcomes in diabetic patients undergoing $\mathrm{CABG},{ }^{9,10}$ even in the setting of a general surgical intensive care unit (ICU). ${ }^{11}$ In October 2002, a local protocol of perioperative/in-hospital strict glycemic control in diabetic patients started in our institution. Its efficacy has been shown in a series of 200 consecutive diabetic patients undergoing on-pump cardiac surgery. ${ }^{12}$ According to their insulin response, patients were divided into good $(n=165)$ and poor $(\mathrm{n}=35)$ responders. The protocol enabled us to postoperatively attain a mean blood glucose concentration of $8.21 \pm 2.28 \mathrm{mmol} / \mathrm{L}(148 \pm 41 \mathrm{mg} / \mathrm{dL})$ in good responders and $11.54 \pm 3.00 \mathrm{mmol} / \mathrm{L}(208 \pm 54 \mathrm{mg} / \mathrm{dL})$ in poor responders. Afterward, we sought to evaluate this protocol's effect on the expected mortality of a diabetic patient population undergoing myocardial revascularization. The observed and expected mortalities were compared according to the EuroSCORE risk evaluation model. ${ }^{13}$ Therefore, our primary goal was to estimate the effect of strict glycemic control on the EuroSCORE expected mortality. Nevertheless, we choose to include a control group to verify that the EuroSCORE model did not overestimate mortality. Reduction of potential bias was attempted by adding a propensity score analysis. ${ }^{14,15}$

\section{Materials and Methods Patients}

This study was approved by our ethical committee (Comité de Protection des Personnes se Prêtant à la Recherche Biomédicale, CCPPRB Pitié-Salpêtrière, Paris, France). Although patient care conformed to the standard procedure currently used at our institute, written informed consent was obtained from each patient included in this study. Since October 2002, all patients with DM undergoing cardiac surgery at our institution have been receiving a protocol of insulin administration for glycemic control. A 2-month period was needed to ensure full implementation of the protocol and to achieve nursing compliance. All patients with DM undergoing CABG between January 2003 and June 2004, alone or in association with other procedures, were included in this study (protocol group, group $\mathrm{P} ; \mathrm{n}=300$ ). The following preoperative variables, needed for EuroSCORE estimation, were prospectively entered into our database: age, sex, chronic obstructive pulmonary disease (COPD) on therapy, extracardiac arteriopathy, neurological dysfunction disease, previous cardiac surgery, serum creatinine levels of greater than $200 \mu \mathrm{mol} / \mathrm{L}$, active endocarditis, critical preoperative status, unstable angina, left ventricular ejection fraction (LVEF) of $30 \%$ to $50 \%$ or less than $30 \%$, recent $\mathrm{MI}(<90$ days), systolic pulmonary artery pressure of greater than $60 \mathrm{~mm}$ $\mathrm{Hg}$, emergency, previous coronary angioplasty, number of diseased vessels, left main coronary trunk stenosis of greater than $50 \%$, major cardiac procedures in addition to $\mathrm{CABG}$, operation on the thoracic aorta, and postinfarction septal rupture. Other preoperative variables entered were type of DM therapy (oral drugs or insulin), body mass index, previous coronary angioplasty, number of diseased vessels, and left main coronary trunk stenosis of greater than $50 \%$. The patients were divided into 2 risk classes, according to their additive EuroSCORE values: low-moderate risk (EuroSCORE, 0-4) and moderate-high risk (EuroSCORE, $>4$ ). The logistic EuroSCORE algorithm was used to assign to every patient an expected death probability. A mean logistic EuroSCORE value was calculated for each risk class, aiming to compare observed and expected mortality.

As previously anticipated, a control group was selected including a series of 300 consecutive diabetic patients (no protocol group, group NP) who underwent CABG between March 2001 and September 2002 just before the introduction of the protocol. Preoperative characteristics of study groups and patient risk profiles are shown in Table 1.

\section{Protocol}

Until October 2002, glucose control started on the patient's arrival at the ICU. No attempt to control blood glycemic levels (BGLs) was performed the day before surgical intervention and even during surgical intervention. Once in the ICU, fast-acting insulin (Actrapid HM; Novo Nordisk Pharmaceutique, Puteaux, France) was administered subcutaneously, according to the following protocol: less than $6.66 \mathrm{mmol} / \mathrm{L}(120 \mathrm{mg} / \mathrm{dL}), 0 \mathrm{U} ; 6.66$ to 8.33 $\mathrm{mmol} / \mathrm{L}(120-150 \mathrm{mg} / \mathrm{dL}), 2 \mathrm{U} ; 8.38$ to $9.99 \mathrm{mmol} / \mathrm{L}$ (151-180 $\mathrm{mg} / \mathrm{dL}), 4 \mathrm{U} ; 10.05$ to $11.66(181-210 \mathrm{mg} / \mathrm{dL}), 6 \mathrm{U}$; and greater than $11.66 \mathrm{mmol} / \mathrm{L}(210 \mathrm{mg} / \mathrm{dL}), 8 \mathrm{U}$.

Since October 2002, all treated diabetic patients undergoing cardiac procedures at our institution have been receiving a protocol to standardize the titration of insulin therapy during the perioperative period. This protocol, which has been extensively described elsewhere, ${ }^{12}$ has not changed during the timeframe of the study. Briefly, all preoperative diabetic therapies were withdrawn the evening before the operation and were substituted with $0.15 \mathrm{U} / \mathrm{kg}$ subcutaneous intermediary insulin (Umuline NPH; Lilly, Suresnes, France), with additional subcutaneous fast-acting insulin (Actrapid 
TABLE 1. Preoperative characteristics

\begin{tabular}{|c|c|c|c|c|}
\hline & All & Group P & Group NP & $P$ value \\
\hline No. of patients & 600 & 300 & 300 & \\
\hline Age (y) & $66 \pm 10$ & $66 \pm 10$ & $66 \pm 10$ & .80 \\
\hline $\operatorname{Sex}(F)$ & $142(24 \%)$ & $69(23 \%)$ & $73(24 \%)$ & .70 \\
\hline \multicolumn{5}{|l|}{ Diabetic control } \\
\hline Oral & $437(73 \%)$ & $212(71 \%)$ & $225(75 \%)$ & .23 \\
\hline Insulin & $163(27 \%)$ & $88(29 \%)$ & $75(25 \%)$ & .23 \\
\hline $\mathrm{BMI}$ & $28 \pm 5$ & $27 \pm 4$ & $28 \pm 6$ & .66 \\
\hline $\mathrm{BMI}>30$ & $149(25 \%)$ & $75(25 \%)$ & $74(25 \%)$ & .92 \\
\hline COPD on therapy & $29(5 \%)$ & $23(8 \%)$ & $6(2 \%)$ & $<.01$ \\
\hline Extracardiac arteriopathy & $100(17 \%)$ & $58(19 \%)$ & $42(14 \%)$ & .08 \\
\hline Neurological dysfunction disease & $27(5 \%)$ & $16(5 \%)$ & $11(4 \%)$ & .32 \\
\hline Previous cardiac surgery & $15(3 \%)$ & $7(2 \%)$ & $8(3 \%)$ & .79 \\
\hline Serum creatinine $>200 \mu \mathrm{mol} / \mathrm{L}$ & $20(3 \%)$ & $7(2 \%)$ & $13(4 \%)$ & .17 \\
\hline Active endocarditis & $0(0 \%)$ & $0(0 \%)$ & $0(0 \%)$ & \\
\hline Critical preoperative status & $8(1 \%)$ & $6(2 \%)$ & $1(1 \%)$ & .15 \\
\hline Unstable angina & $61(10 \%)$ & $37(12 \%)$ & $24(8 \%)$ & .08 \\
\hline LVEF dysfunction (30\%-50\%) & $199(33 \%)$ & $96(32 \%)$ & $103(34 \%)$ & .54 \\
\hline LVEF dysfunction $(<30 \%)$ & $19(3 \%)$ & $5(2 \%)$ & $14(5 \%)$ & .04 \\
\hline Recent $\mathrm{MI}(<90 \mathrm{~d})$ & $31(5 \%)$ & $26(9 \%)$ & $5(2 \%)$ & $<.01$ \\
\hline Systolic PA pressure $>60 \mathrm{~mm} \mathrm{Hg}$ & $0(0 \%)$ & $0(0 \%)$ & $0(0 \%)$ & \\
\hline Emergency & $47(8 \%)$ & $21(7 \%)$ & $26(5 \%)$ & .45 \\
\hline Previous PTCA & $105(18 \%)$ & $51(17 \%)$ & $54(18 \%)$ & .75 \\
\hline Left main trunk $>50 \%$ & $121(19 \%)$ & $62(21 \%)$ & $59(20 \%)$ & .76 \\
\hline No. of diseased vessels & $2.6 \pm 0.6$ & $2.5 \pm 0.6$ & $2.6 \pm 0.6$ & .20 \\
\hline Major associated procedures & $92(15 \%)$ & $39(13 \%)$ & $53(18 \%)$ & .11 \\
\hline Operation on thoracic aorta & $1(0.2 \%)$ & $1(0.3 \%)$ & $0(0 \%)$ & .32 \\
\hline Postinfarction septal rupture & $1(0.2 \%)$ & $1(0.3 \%)$ & $0(0 \%)$ & .32 \\
\hline EuroSCORE (additive) & $4.04 \pm 2.90$ & $4.16 \pm 2.98$ & $3.93 \pm 2.90$ & .34 \\
\hline EuroSCORE (logistic) & $4.10 \pm 5.62$ & $4.29 \pm 6.32$ & $3.91 \pm 4.83$ & .41 \\
\hline EuroSCORE 0-4 & $372(62 \%)$ & $180(60 \%)$ & $192(64 \%)$ & .31 \\
\hline EuroSCORE $>4$ & $228(38 \%)$ & $120(40 \%)$ & $108(36 \%)$ & .31 \\
\hline
\end{tabular}

$B M I$, Body mass index; $C O P D$, chronic obstructive pulmonary disease; $L V E F$, left ventricular ejection fraction; $M I$, myocardial infarction; $P A$, pulmonary artery; PTCA, percutaneous transluminal coronary angioplasty.

HM) according to BGL. In addition to the implementation of this protocol, an infusion of dextrose solution was started ( $5 \mathrm{~g} / \mathrm{h})$. After BGL measurement, all patients systematically received a further subcutaneous injection of $0.15 \mathrm{U} / \mathrm{kg}$ intermediary insulin on the morning of the operation (Umuline NPH). During the intraoperative period, the infusion of dextrose was maintained at the same rate (ie, $5 \mathrm{~g} / \mathrm{h}$ ), and an aggressive insulin therapy based on continuous infusion of fast-acting insulin (Actrapid HM) was initiated as soon as BGL exceeded $9.99 \mathrm{mmol} / \mathrm{L}$ (180 mg/dL); BGLs were measured immediately after the induction of anesthesia and thereafter at 30-minute intervals. Subsequently, its infusion rate was titrated according to a protocol (see Appendix 1) modified from the Portland protocol. ${ }^{9}$ The objective of the current protocol was to maintain an intraoperative blood glucose concentration of between 8.33 and $11.10 \mathrm{mmol} / \mathrm{L}(150-200 \mathrm{mg} / \mathrm{dL})$. During the postoperative period, all patients were aggressively treated with either subcutaneous or continuous intravenous insulin therapy to maintain a BGL of less than $7.77 \mathrm{mmol} / \mathrm{L}$ (140 mg/dL). Throughout their stay in the ICU, BGL determination was performed on an hourly basis. Once out of the ICU, patients were treated according to the following protocol: intermediary insulin (Umulin NPH) was administered subcutaneously twice daily $(0.15 \mathrm{IU} / \mathrm{kg})$. Additionally, BGLs were adjusted every 4 hours by using subcutaneous fast-acting insulin (Actrapid HM): less than $6.11 \mathrm{mmol} / \mathrm{L}$ (110 mg/dL), $0 \mathrm{U}$; 6.11 to $7.99 \mathrm{mmol} / \mathrm{L}$ (110-144 mg/dL), $2 \mathrm{U}$; 8.05 to $9.93 \mathrm{mmol} / \mathrm{L}(145-179 \mathrm{mg} / \mathrm{dL}), 4 \mathrm{U} ; 9.99$ to 12.15 $\mathrm{mmol} / \mathrm{L}(180-219 \mathrm{mg} / \mathrm{dL}), 6 \mathrm{U}$; and greater than $12.21 \mathrm{mmol} / \mathrm{L}$ (220 mg/dL), $8 \mathrm{U}$.

\section{Statistical Analysis}

Univariate analysis for assessment of the relationships between potential prognostic factors and mortality was performed by using $\chi^{2}$ tests for categoric variables and Student $t$ tests for continuous variables. Death probability was calculated for each patient according to the EuroSCORE logistic model. A logistic regression was performed, with the logit of death probability and protocol status as potential prognostic factors. Separate subgroup logistic regressions were performed for low- to moderate-risk and moderate- to high-risk patients. To measure a model's discrimina- 
tion, c-statistics (area under the receiver operating characteristic curve) were used, and the Hosmer-Lemeshow test was used for goodness-of-fit assessment. A propensity analysis was performed to control for selection bias: a propensity score was calculated for each patient by using logistic regression modeling, which estimated the probability for a patient to receive a protocol of strict glycemic control. Variables used to determine the propensity score were selected among preoperative and intraoperative variables that were significant at a two-tailed nominal $P$ value of less than .20 : LVEF, COPD, recent MI, extracardiac arteriopathy, critical preoperative status, unstable angina, serum creatinine level of greater than $200 \mu \mathrm{mol}$, bilateral thoracic artery revascularization, major associated procedures, and crossclamping duration time. The propensity score was subsequently regressed as an independent covariate by means of quintile stratification in the multivariable logistic regression model, including the logit of death probability and protocol status. A sensitivity analysis was carried out for patients who underwent $\mathrm{CABG}$ without additional procedures: a new propensity score was recalculated and subsequently regressed in the same way as described above. Data are expressed as means \pm standard deviation for continuous variables and numbers and percentages for qualitative variables. All $P$ values were 2 tailed. All statistical analyses were performed with the SAS V8 statistical package (SAS Institute, Inc, Cary, NC).

\section{Major Outcomes}

The primary outcome was in-hospital mortality. Causes of morbidity were defined as follows: (1) cardiac (low cardiac output and/or hypotension treated with an intra-aortic balloon pump and/or $\geq 2$ intravenous inotropes or vasopressors over more than 24 hours, malignant arrhythmia [asystole, ventricular tachycardia, or ventricular fibrillation] requiring cardiopulmonary resuscitation, antiarrhythmia therapy or defibrillator implantation); (2) respiratory (mechanical ventilation for $>48$ hours, reintubation, tracheostomy); (3) neurological (focal brain injury with permanent functional deficit, irreversible encephalopathy); (4) renal (acute renal failure necessitating dialysis); and (5) infectious (septic shock with positive blood culture results, deep sternal or leg wound infection requiring intravenous antibiotics and/or surgical debridement).

\section{Results}

\section{Preoperative Characteristics}

EuroSCORE risk profiles were similar in both groups. Mean additive and logistic EuroSCORE values were, respectively, $4.16 \pm 2.98$ and $4.29 \pm 6.32$ in group $\mathrm{P}$ versus $3.93 \pm 2.90$ and $3.91 \pm 4.83$ in group NP. Furthermore, the distribution of patients across the 2 risk classes was similar in both groups: $180(60 \%)$ patients in group P versus 192 (64\%) in group NP were in the low- to moderate-risk class (EuroSCORE, 0-4), and $120(40 \%)$ in group P versus $108(36 \%)$ in group NP were in the high- to moderate-risk class (EuroSCORE, $>4$ ). The following preoperative characteristic variables were significantly different in the 2 groups: COPD, LVEF of less than $30 \%$, and recent $\mathrm{MI}$.
BGL mmol/L

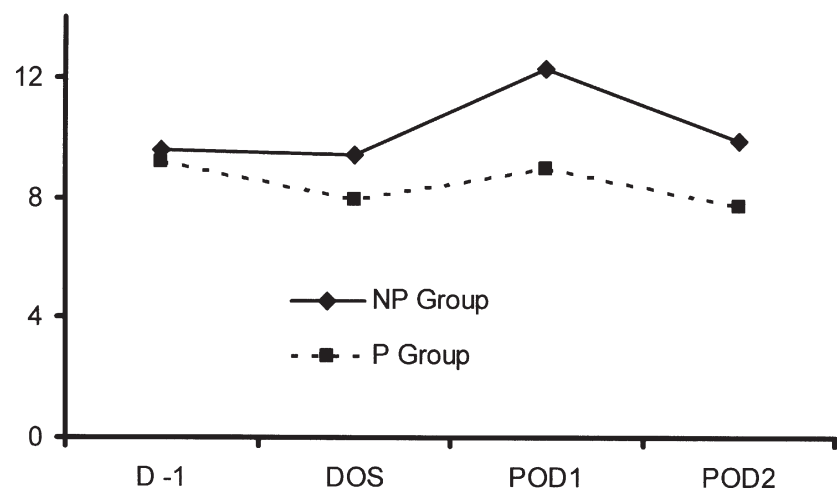

Fig 1. Mean blood glycemic level (BGL) trends. $D-1$, Day before the operation, $P=.30 ; D O S$, day of the operation, $P<.001 ; P O D$ 1 and $P O D$ 2, postoperative days 1 and $2, P<.001$.

\section{Glucose Control}

Mean BGL trends of both groups are shown in Figure 1. Preoperative mean BGLs were not significantly different between the 2 groups: $9.19 \pm 3.90 \mathrm{mmol} / \mathrm{L}(166 \pm 70$ $\mathrm{mg} / \mathrm{dL})$ in group $\mathrm{P}$ versus $9.55 \pm 1.28(172 \pm 23 \mathrm{mg} / \mathrm{dL})$ in group NP $(P=0.30)$. The BGLs at the end of the operation and on postoperative days 1 and 2 were significantly lower in group P. Moreover, the lower standard error of mean postoperative BGLs means a more uniform control of glycemic levels in group $\mathrm{P}$ (Table 2).

\section{Postoperative Results}

Details of operative data and associated procedures, as well as postoperative mortality and morbidity, are presented in Table 2 .

The most important difference between the 2 groups was the number of patients having a bilateral internal thoracic artery (ITA) revascularization: $134(45 \%)$ in group P versus $38(13 \%)$ in group NP $(P<.01)$. This difference reflects our more recent policy of extensive arterial revascularization using both ITAs, even in diabetic patients.

Seminal cause of death in group $\mathrm{P}$ was cardiogenic shock in $3(1 \%)$ patients and pneumonia in $1(0.3 \%)$ patient. Main cause of death in group NP was cardiogenic shock in 7 $(2.3 \%)$ patients, cardiac arrhythmia in $2(0.7 \%)$ patients, respiratory distress syndrome in $2(0.7 \%)$ patients, and stroke in $1(0.3 \%)$ patient. Overall mortality was $1.3 \%$ (4 patients) in group $\mathrm{P}$ versus $4.0 \%$ in group NP (12 patients; $P<.05)$. Death occurred more frequently in patients who underwent $\mathrm{CABG}$ with associated procedures: $1 \%$ for isolated $\mathrm{CABG}$ versus $3 \%$ for $\mathrm{CABG}$ and associated procedures in group P, $2 \%$ for isolated CABG versus $13 \%$ for $\mathrm{CABG}$ and associated procedures in group $\mathrm{NP}$, and $1 \%$ for isolated $\mathrm{CABG}$ versus $9 \%$ for $\mathrm{CABG}$ and associated pro- 
Table 2. Operative data and postoperative results

\begin{tabular}{|c|c|c|c|c|}
\hline & All & Group P & Group NP & $P$ value \\
\hline CPB time (min) & $71 \pm 29$ & $72 \pm 29$ & $70 \pm 30$ & .40 \\
\hline Crossclamp time (min) & $53 \pm 24$ & $55 \pm 25$ & $52 \pm 24$ & .08 \\
\hline Off pump & $30(5 \%)$ & $13(4 \%)$ & $17(6 \%)$ & .45 \\
\hline No. of grafts per patient & $2.6 \pm 0.8$ & $2.7 \pm 0.9$ & $2.6 \pm 0.8$ & .18 \\
\hline No ITA & $14(2 \%)$ & $5(2 \%)$ & $9(3 \%)$ & .28 \\
\hline Single ITA & $414(69 \%)$ & $161(54 \%)$ & $253(84 \%)$ & $<.01$ \\
\hline Bilateral ITA & $172(29 \%)$ & $134(45 \%)$ & $38(13 \%)$ & $<.01$ \\
\hline Associated procedures & $92(15 \%)$ & $39(13 \%)$ & $53(18 \%)$ & .11 \\
\hline AVR & $45(8 \%)$ & $22(7 \%)$ & $23(8 \%)$ & .88 \\
\hline AVR + MVR & $3(1 \%)$ & $1(0.3 \%)$ & $2(1 \%)$ & .56 \\
\hline AVR + mitral repair & $2(0.3 \%)$ & $1(0.3 \%)$ & $1(0.3 \%)$ & 1.00 \\
\hline MVR & $2(0.3 \%)$ & $0(0 \%)$ & $2(1 \%)$ & .16 \\
\hline Mitral repair & $9(2 \%)$ & $3(1 \%)$ & $6(2 \%)$ & .31 \\
\hline Carotid endarterectomy & $26(4 \%)$ & $9(3 \%)$ & $17(6 \%)$ & .11 \\
\hline Aorta/brachiocephalic trunk artery graft & $1(0.2 \%)$ & $0(0 \%)$ & $1(0.3 \%)$ & .32 \\
\hline Bentall procedure & $1(0.2 \%)$ & $1(0.3 \%)$ & $0(0 \%)$ & .32 \\
\hline Septal myomectomy & $1(0.2 \%)$ & $1(0.3 \%)$ & $0(0 \%)$ & .32 \\
\hline Septal defect closure & $1(0.2 \%)$ & $1(0.3 \%)$ & $0(0 \%)$ & .32 \\
\hline Myxoma resection & $1(0.2 \%)$ & $0(0 \%)$ & $1(0.3 \%)$ & .32 \\
\hline Mortality & $16(3 \%)$ & $4(1.3 \%)$ & $12(4.0 \%)$ & .04 \\
\hline \multicolumn{5}{|l|}{ Mean blood glucose level (mmol/L) } \\
\hline Evening before operation & $9.37 \pm 4.16$ & $9.19 \pm 3.90$ & $9.56 \pm 4.42$ & .30 \\
\hline Day of operation & $8.61 \pm 3.35$ & $7.89 \pm 2.52$ & $9.40 \pm 3.92$ & $<.001$ \\
\hline Postoperative day 1 & $10.55 \pm 3.97$ & $8.94 \pm 2.60$ & $12.29 \pm 4.45$ & $<.001$ \\
\hline Postoperative day 2 & $8.80 \pm 3.11$ & $7.72 \pm 2.42$ & $9.89 \pm 3.34$ & $<.001$ \\
\hline Mean postoperative blood glycemic level & $9.29 \pm 2.43$ & $8.19 \pm 1.58$ & $10.48 \pm 2.62$ & $<.001$ \\
\hline Morbidity & $77(13 \%)$ & $41(14 \%)$ & $36(12 \%)$ & .54 \\
\hline Cardiac & $55(9 \%)$ & $30(10 \%)$ & $25(8 \%)$ & .48 \\
\hline Pulmonary & $27(5 \%)$ & $16(5 \%)$ & $11(4 \%)$ & .32 \\
\hline Neurological & $15(3 \%)$ & $7(2 \%)$ & $8(3 \%)$ & .79 \\
\hline Renal & $8(1 \%)$ & $3(1 \%)$ & $5(2 \%)$ & .48 \\
\hline Infectious & $41(7 \%)$ & $24(8 \%)$ & $17(6 \%)$ & .26 \\
\hline Mediastinitis & $24(4 \%)$ & $14(5 \%)$ & $10(3 \%)$ & .40 \\
\hline
\end{tabular}

CPB, Cardiopulmonary bypass; ITA, internal thoracic artery; AVR, aortic valve replacement; $M V R$, mitral valve replacement.

cedures in the whole population. There was no difference of morbidity between the 2 groups.

\section{Risk Factors for Operative Mortality}

According to univariate analysis, the following variables yielded as a risk factor for operative mortality. Among preoperative characteristics not used for EuroSCORE risk estimation, only the absence of a protocol yielded as a predictor of mortality $(P=.0426)$. Among single variables entered in the EuroSCORE model, extracardiac arteriopathy $(P=.0234)$, previous cardiac surgery $(P=.0094)$, serum creatinine level of greater than $200 \mu \mathrm{mol} / \mathrm{L}(P=.0384)$, LVEF of less than $30 \%(P<.0001)$, and major associated procedures, $(P<.0001)$ were risk factors for operative mortality. Additive and logistic EuroSCORE values were confirmed to be excellent predictors of mortality $(P=.0008$ and $P=.0104)$. Among operative data, no use of ITAs
$(P<.0001)$ and cardiopulmonary bypass and crossclamping duration times $(P=.0031$ and $P=.0009)$ were risk factors for operative mortality. The use of both ITAs for myocardial revascularization did not affect operative mortality at univariate analysis $(P=.37)$.

\section{Expected and Observed Mortality}

Comparisons between mean observed and expected mortalities are shown in Figure 2. Observed mortality in group $\mathrm{P}$ was lower than the expected mortality for the entire group, as well as for each risk class: $0.6 \%$ versus $1.8 \%$ (low-moderate risk), $2.5 \%$ versus $8.0 \%$ (moderatehigh risk, $P=.03$ ), and $1.3 \%$ versus $4.3 \%$ (entire group, $P=.01)$. On the other hand, there was no difference between observed and expected mortality in group NP: $1.6 \%$ versus $1.9 \%$ (low-moderate risk), $8.3 \%$ versus $7.5 \%$ (moderate-high risk), and $4.0 \%$ versus $3.9 \%$ (entire group). 
P Group: Observed vs Expected Mortality

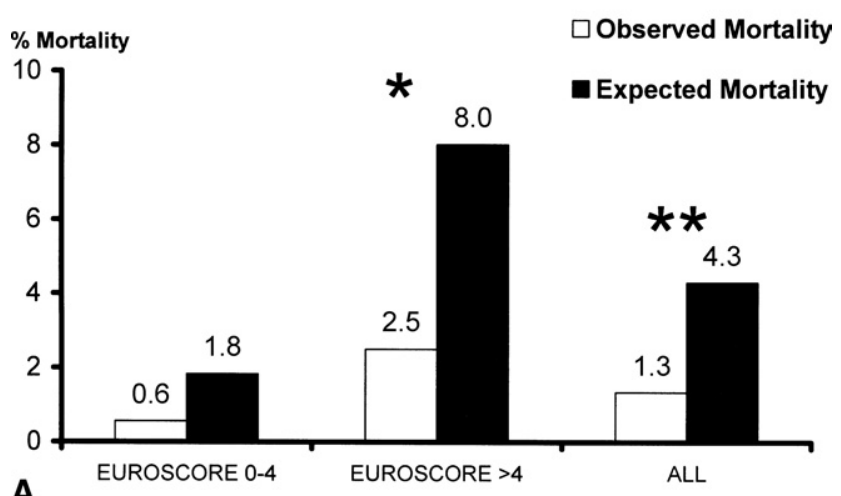

NP Group: Observed vs Expected Mortality

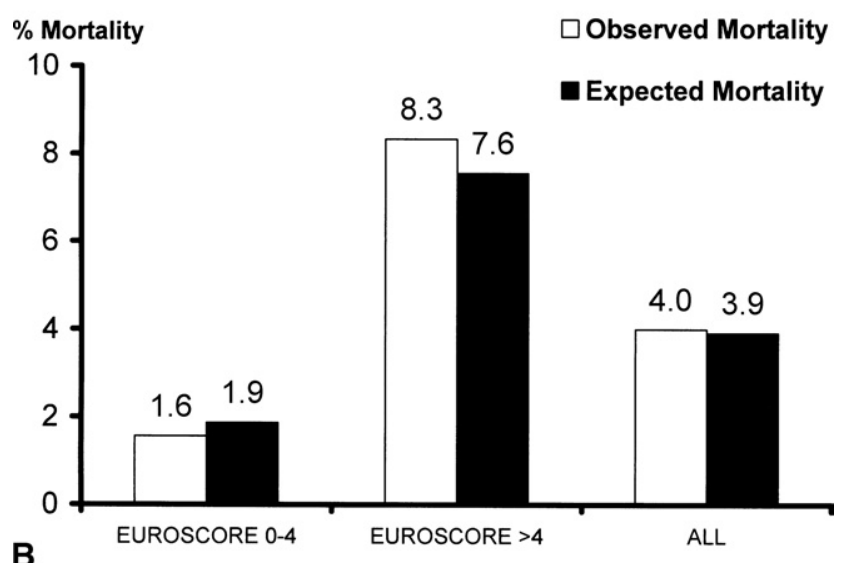

Fig 2. A, Comparison between observed and expected mortality in group $P . \chi^{2}$ Test: ${ }^{*} \boldsymbol{P}=.03,{ }^{*} \boldsymbol{P}=.01$. $\mathrm{B}$, Comparison between observed and expected mortality in group NP.

Logistic regression showed the EuroSCORE to overestimate mortality in patients receiving the protocol $\left(\mathrm{U}_{\mathrm{cal}}=2.183, P<\right.$ .03), but it confirmed the EuroSCORE to well predict mortality for patients not receiving the protocol $(\mathrm{Ucal}=0.0854)$. After risk adjustment for the EuroSCORE logistic value, multivariable analysis showed the protocol of glycemic control to reduce the odds of mortality by $72 \%$ (odds ratio [OR], $0.282 ; 95 \%$ confidence interval, 0.092-0.859; $P<.03$ ). Subgroup analysis showed the moderate- to high-risk group of patients to receive the greatest benefit from strict glycemic control. For patients with a EuroSCORE of greater than 4 , the protocol improved mortality (OR, $0.24 ; P<.05$ ), whereas no significant improvement was found in low- to moderate-risk patients (OR, $0.36 ; P=.3819)$. When included in the multivariable analysis, the use of both ITAs for myocardial revascularization did not affect operative mortality $(P=.3186)$.
Addition of the propensity score to the multivariable analysis did not significantly displace $P$ values and ORs, with the protocol being associated with an OR of 0.24 $(P<.03)$. Sensitivity analysis of patients who underwent CABG without additional procedures showed the protocol to maintain its protective effect with an OR of 0.15 $(P<.05$, Table 3$)$.

\section{Discussion}

Importance of Glucose Control

These findings clearly demonstrate that optimal glucose control reduces EuroSCORE expected mortality in diabetic patients undergoing CABG. Much evidence has recently shown that glucose control might play a key role in perioperative care of diabetic coronary patients. Moreover, perioperative hyperglycemia has been recognized as an independent predictor for outcome in diabetic ${ }^{12,16,17}$ and even in nondiabetic ${ }^{17}$ patients.

Although adequate glycemic control has been found to be efficiently achieved by a steady infusion of insulin, ${ }^{10}$ we chose an intermittent dosing performed during the operative period; the infusion rate of insulin was subsequently titrated according to a protocol modified from the Portland protocol. Our results, as in the work of Furnary and coworkers, ${ }^{9}$ confirm that a better control of glucose levels, achieved by means of a protocol of insulin administration, reduces mortality in diabetic patients; the author accounts for this mortality reduction by a significant reduction in cardiac-related mortality. It still remains unclear whether strict glycemic control improves early clinical outcomes by preventing the detrimental effects of high blood glucose concentrations. The beneficial effects of glycemic control might be directly related to the metabolic effects of insulin. Maintenance of normoglycemia during cardiac procedures has been claimed to be unattainable, even with intensive insulin therapy, which, on the other hand, could be harmful by initiating hypoglycemia. ${ }^{18}$ As Carvalho and associates ${ }^{19}$ advocate, we started our protocol on overnight fasting together with dextrose infusions: indeed, administration of glucose and insulin before surgical intervention is different from most insulin protocols, which are initiated at the time of the operation. ${ }^{9,10}$ Our approach, coupled with the withdrawal of any preoperative treatment, allowed us to achieve not only tight glycemic control but also more uniform control of glycemic variations, as suggested by the lower standard error of postoperative BGLs in group P. Moreover, starting infusion on the evening before the operation means an earlier beginning of insulin therapy. Indeed, mortality reduction in the study by Van der Berghe and colleagues ${ }^{11}$ was evident only among patients who remained in the ICU for 5 days or longer. Hence, as Schricker and Carvalho argued, ${ }^{20}$ we also think that an 
Table 3. Multivariable analysis of mortality in patients with diabetes mellitus undergoing coronary artery bypass grafting

\begin{tabular}{|c|c|c|c|c|c|}
\hline & Variable & $\mathrm{OR}$ & $95 \% \mathrm{Cl}$ & $P$ value & c-Statistics \\
\hline \multirow[t]{3}{*}{ EuroSCORE 0-4 } & & & & & 0.830 \\
\hline & Protocol & 0.361 & $0.09-0.86$ & .3819 & \\
\hline & EuroSCORE & 20.076 & $0.84-476.90$ & .0635 & \\
\hline \multirow[t]{3}{*}{ EuroSCORE $>4$} & & & & & 0.788 \\
\hline & Protocol & 0.236 & $0.06-0.96$ & .0441 & \\
\hline & EuroSCORE & 2.809 & $1.49-5.29$ & .0014 & \\
\hline \multirow[t]{3}{*}{ Whole population } & & & & & 0.833 \\
\hline & Protocol & 0.282 & $0.09-0.86$ & .0260 & \\
\hline & EuroSCORE & 2.752 & $2.26-3.35$ & $<.0001$ & \\
\hline \multirow[t]{3}{*}{ Whole population* } & & & & & 0.839 \\
\hline & Protocol & 0.241 & $0.06-0.90$ & .0344 & \\
\hline & EuroSCORE & 2.759 & $2.21-3.43$ & $<.0001$ & \\
\hline \multirow[t]{3}{*}{ CABG only $†$} & & & & & 0.763 \\
\hline & Protocol & 0.155 & $0.02-0.84$ & .0310 & \\
\hline & EuroSCORE & 2.78 & $2.18-3.55$ & $<.0001$ & \\
\hline
\end{tabular}

OR, Odds ratio; $95 \% \mathrm{Cl}, 95 \%$ confidence interval; $C A B G$, coronary artery bypass grafting. ${ }^{*}$ Whole population after addition of propensity score in the model. tSensitivity analysis: patients receiving coronary artery bypass grafting without additional procedures after addition of propensity score in the model.

earlier and more aggressive approach might further improve early outcomes.

\section{Observed and Expected Mortality}

Since the introduction of a protocol for perioperative control of glycemic levels, we have quantified its effect on patients' outcomes. Therefore we chose the EuroSCORE risk stratification algorithm, the most rigorously evaluated scoring system in cardiac surgery, ${ }^{21}$ with an excellent discriminatory power to predict 30-day mortality for patients undergoing $\mathrm{CABG}^{22}$ and even valve surgery. ${ }^{23}$ The additive EuroSCORE model ${ }^{13}$ was used to divide patients according to their risk values and to compare risk profiles between the 2 groups. To compare observed and expected deaths, we chose the Logistic EuroSCORE model. ${ }^{24,25}$ Recently, EuroSCORE has been claimed to overestimate mortality. ${ }^{26}$ Jin and Grunkemeier $^{27}$ suggested to recalibrate the logistic EuroSCORE model by setting the logistic probability equal to the ratio of total observed deaths to predicted deaths (O/E ratio). Knowing that the $\mathrm{O} / \mathrm{E}$ ratio in group $\mathrm{NP}$, our referring population, is $4.0 / 3.9 \cong 1$, we assumed the model did not need to be recalibrated.

Simple univariate comparisons on the basis of mean observed and expected mortalities demonstrate that observed and expected mortalities in group NP are quite the same, whereas observed mortality in group $\mathrm{P}$ is significantly lower than the expected mortality. Furthermore, as recommended, ${ }^{28}$ we performed a new logistic regression with the logit of EuroSCORE death probability as a risk factor: the protocol of insulin administration highly improved outcomes in diabetic patients, reducing by $72 \%$ the probability of death (OR, 0.28; 95\% confidence interval, 0.092-0.859). These results were not significantly displaced by the addition of a propensity score in the model.
Both univariate and multivariate analyses showed the protocol to significantly improve outcomes in moderate- to high-risk patients (EuroSCORE, >4). Moreover, these results outlined that higher-risk patients receive the greatest benefit from a strict glycemic control, resulting in a high improved $\mathrm{O} / \mathrm{E}$ ratio. Indeed, overall mortality reduction is mostly explained by outcomes improvements in such patients.

However, statistically speaking, outcome improvements in low-risk patients are difficult to effect, because the mortality rate in such patients is obviously already low. Finally, we do not definitively know whether tight glycemic control in lower-risk patients is not useful at all or its benefits are simply too difficult to demonstrate.

\section{Bilateral ITA Revascularization}

Recently, we adopted a policy of extensive arterial revascularization $^{29}$ using both ITAs, even in diabetic patients, but this approach did not have a significant effect on operative mortality. Thoracic arteries were harvested as skeletonized grafts to minimize sternal devascularization and reduce the risk of mediastinitis. ${ }^{30}$ It has been demonstrated that glucose control reduces the risk of sternal wound infection. ${ }^{31,32} \mathrm{We}$ could not appreciate this positive effect, probably because it was counterbalanced in group $\mathrm{P}$ by the higher proportion of patients undergoing a bilateral ITA revascularization, a well-known risk factor for mediastinitis. ${ }^{33}$

\section{CABG and Associated Procedures}

The two most important works on preoperative glycemic control in diabetic patients undergoing coronary surgery 9,10 were focused on a homogenous population of patients undergoing isolated CABG. Sensitivity analysis of patients who underwent $\mathrm{CABG}$ without additional procedures showed the 
protocol to maintain its protective effect. We included patients undergoing $\mathrm{CABG}$ in association with other procedures because the inclusion of more complex patients increased risk profiles and enhanced outcome differences over a relatively short period, 3 years in this study. This might further reduce the effect of all minute nonmeasurable improvements in anesthesia, operative technique, and postoperative care that contribute to the reduction of early mortality over a longer period. Combined procedures were associated with a higher EuroSCORE value, and as expected, death occurred more frequently in such patients. Associated procedures did not carry a dramatically higher mortality in group $\mathrm{P}$, probably because of the protective effect of the strict glycemic control on higher-risk patients, resulting in a highly improved $\mathrm{O} / \mathrm{E}$ ratio.

\section{Limits}

Although the study was prospectively designed, the comparison between groups $\mathrm{P}$ and NP was nonrandomized. A better control of glucose levels was known to have positive effects on patient outcomes, and therefore we considered a randomized study design unethical. We added a propensity score analysis to limit bias of nonrandomized comparison.

We do not know why morbidity and mortality outcomes did not follow the same improvement trend. We could speculate that the absence of improvements in morbidity outcomes between the 2 groups should be explained by the composite nature of morbidity criteria and by the prospective design of the protocol study group, probably resulting in a better detection and collection of morbidity events.

It is well known that infections should have been reduced by a better glycemic control. ${ }^{31,32}$ We think that the lack of difference between the 2 groups might take into account the highest rate of bilateral ITA harvesting in the protocol group.

Finally, although our results showed a clear benefit for patients receiving the protocol, our specific method of glycemic control might not be considered the standard practice in most centers: a good nursing compliance is mandatory, and furthermore, the multiple steps required for the protocol, even before surgical intervention, might not be easy to follow.

\section{Conclusions}

Diabetes represents one of the most frequent comorbidities in patients undergoing $\mathrm{CABG}$. Fortunately, recent evidence showed that a tight glucose control could improve outcomes in such patients, and we could quantify this mortality reduction, with an OR of 0.28. Higher-risk patients receive the greatest benefit from a strict glycemic control, resulting in a high improved $\mathrm{O} / \mathrm{E}$ ratio. This approach allowed us to perform CABG in diabetic patients, half of whom had bilateral ITA grafting with $1.3 \%$ operative mortality, a figure not much higher than the $1.0 \%$ in-hospital mortality recently reported in a series of 1142 diabetic patients undergoing angioplasty in the state of New York. ${ }^{34}$

Therefore, optimal glucose control should become a widespread gold standard of perioperative care in diabetic patients. Further studies need to be performed to eventually integrate DM and its control in the EuroSCORE risk stratification algorithm.

We thank Martine Collomb for her kindly English revision of the article.

\section{References}

1. Bonow RO, Gheorghiade M. The diabetes epidemic: a national and global crisis. Am J Med. 2004;116(suppl 5A):2S-10S.

2. Kannel WB, McGee DL. Diabetes and cardiovascular risk: the Framingham study. JAMA. 1979;241:2035-8.

3. Flaherty JD, Davidson JC. Diabetes and coronary revascularization. JAMA. 2005;293:1501-8.

4. Edwards FH, Grower FL, Shroyer AL, Schwartz M, Bero J. The Society of Thoracic Surgeons National Cardiac Surgery Database: current risk assessment. Ann Thorac Surg. 1997;63:903-8.

5. Calafiore AM, Di Mauro M, Di Giammarco G, Contini M, Vitolla G, Iaco AL, et al. Effect of diabetes on early and late survival after isolated first coronary bypass surgery in multivessel disease. $J$ Thorac Cardiovasc Surg. 2003;125:144-54.

6. Thourani VH, Weintraub WS, Stein B, Gebhart SSP, Craver MJ, Jones EL, et al. Influence of diabetes mellitus on early and late outcome after coronary artery bypass grafting. Ann Thorac Surg. 1999;67:1045-52.

7. Barsness GW, Peterson ED, Ohmam EM, Nelson CL, DeLong ER, Reves JG, et al. Relationship between diabetes mellitus and long-term survival after coronary bypass and angioplasty. Circulation. 1997;96: 2551-6.

8. Malmberg K, Ryden L, Hamsten A, Efendic S, Herlitz J, Nicol P, et al. Randomized trial of insulin-glucose infusion followed by subcutaneous insulin treatment in diabetic patients with acute myocardial infarction (DIGAMI study): effects on mortality at 1 year. $\mathrm{J} \mathrm{Am} \mathrm{Coll}$ Cardiol. 1995;26:57-65.

9. Furnary AP, Gao G, Grunkemeier GL, Wu Y, Zerr KJ, Bookin SO, et al. Continuous insulin infusion reduces mortality in patients with diabetes undergoing coronary artery bypass grafting. J Thorac Cardiovasc Surg. 2003;125:1007-21.

10. Lazar HL, Chipkin SR, Fitzgerald CA, Bao Y, Cabtal H, Apstein CS Tight glycemic control in diabetic coronary bypass graft patients improves perioperative outcomes and decreases recurrent ischemic event. Circulation. 2004;109:1497-502.

11. Van den Berghe G, Wouters P, Weekers F, Verwaest C, Bruyninckx F, Schetz M, et al. Intensive insulin therapy in the critically ill patients. N Engl J Med. 2001;345:1359-67.

12. Ouattara A, Lecomte P, Le Manach Y, Landi M, Jacqueminet S, Platonov I, et al. Poor intraoperative blood glucose control is associated with a worsened hospital outcome after cardiac surgery in diabetic patients. Anesthesiology. 2005;103:687-94.

13. Nashef SAM, Roques F, Michel P, Gauducheau E, Lemeshow S, Salamon R, et al. European system for cardiac operative risk evaluation (EuroSCORE). Eur J Cardiothorac Surg. 1999;16:9-13.

14. D'Agostino RB Jr. Tutorial in biostatistics: propensity score methods for bas reduction in the comparison of a treatment to a non-randomized control group. Stat Med. 1998;17:2265-81.

15. Blackstone EH. Comparing apples and oranges. J Thorac Cardiovasc Surg. 2002;123:8-15.

16. Furnary AP, Zerr KJ, Grunkemeier GL, Heller CA. Hyperglycemia: a predictor of mortality following CABG in diabetics. Circulation. 1999;100(suppl):I591.

17. Doenst T, Wijeysundera D, Karkouti K, Zechner C, Maganti M, Rao V, et al. Hyperglycemia during cardiopulmonary bypass is an independent 
risk factor for mortality in patients undergoing cardiac surgery. $J$ Thorac Cardiovasc Surg. 2005;130:1144-50.

18. Chaney MA, Nikolov MP, Blakerman BP, Bakhos M. Attempting to maintain normoglycemia during cardiopulmonary bypass with insulin may initiate postoperative hypoglycemia. Anesth Analg. 1999;99: 1091-5.

19. Carvalho G, Moore A, Qizilbash B, Lachapelle K, Schricker T. Maintenance of normoglycemia during open cardiac surgery. Anesth Analg. 2004;99:319-24.

20. Schricker T, Carvalho G. Pro: tight perioperative glycemic control. J Cardiothorac Vasc Anesth. 2005;19:684-8.

21. Gogbashian A, Sedrakyan A, Treasure T. EuroSCORE: a systematic review of international performance. Eur J Cardiothorac Surg. 2004; 25:695-700.

22. Nilsson J, Algotsson L, Höglund P, Lührs C, Brandt J. Early mortality in coronary bypass surgery: the EuroSCORE versus The Society of Thoracic Surgeons risk algorithm. Ann Thorac Surg. 2004;77:1235-9.

23. Toumpoulis IK, Anagnostopoulos CE, Toupoulis SK, DeRose JJ, Swistel DG. EuroSCORE predicts long-term mortality after valve surgery. Ann Thorac Surg. 2005;79:1902-8.

24. Roques F, Michel P, Goldstone AR, Nashef SA. The logistic EuroSCORE. Eur Heart J. 2003;24:881-2.

25. Michel P, Roques F, Nashef SA. The EuroSCORE Project Group. Logistic or additive EuroSCORE for high-risk patients? Eur J Cardiothorac Surg. 2003;23:684-7.

26. Shanmungam G, West M, Berg G. Additive and logistic EuroSCORE performance in high risk patients. Interact Cardio Vasc Thorac Surg. 2005;28:240-3.

27. Jin R, Grunkemeier GL. Does the logistic EuroSCORE offer an advantage over the additive model? Interact Cardio Vasc Thorac Surg. 2006;5:15-7.

28. Peterson ED, Delong ER, Muhlbaier LH, Rosen AB, Buell HE, Kiefe $\mathrm{CI}$, et al. Challenges in comparing risk-adjusted bypass surgery mortality results: results from the Cooperative Cardiovascular Project. J Am Coll Cardiol. 2000;36:2174-84.

29. Lytle BW, Blackstone EH, Loop FD, Houghtaling PL, Arnold JH, Akhrass R, et al. Two internal thoracic artery are better than one. J Thorac Cardiovasc Surg. 1999;117:855-72.

30. Peterson MD, Borger MA, Rao V, Peniston CM, Feindel CM. Skeletonization of bilateral internal thoracic artery grafts lowers the risk of sternal infection in patients with diabetes. J Thorac Cardiovasc Surg. 2003;1236:1314-9.

31. Zerr KJ, Furnary AP, Grunkemeier Gl, Bookin S, Kanhere V, Starr A. Glucose control lowers the risk of wound infection in diabetics after open heart operations. Ann Thorac Surg. 1997;63:356-61.

32. Furnary AP, Zerr KJ, Grunkemeier GL, Starr A. Continuous intravenous insulin infusion reduces the incidence of deep sternal wound infection in diabetic patients after cardiac surgical procedures. Ann Thorac Surg. 1999;67:352-60.

33. Borger MA, Rao V, Weisel RD, Ivanov J, Cohen G, Scully HE, et al. Deep sternal wound infection: risk factors and outcomes. Ann Thorac Surg. 1998;65:1050-6.

34. Wilson SR, Vakili BA, Sherman W, Sanborn TA, Brown DL. Effect of diabetes on long-term mortality following contemporary percutaneous coronary intervention. Diabetes Care. 2004;27:1137-42.

\section{Appendix 1. Intraoperative Insulin Protocol}

The infusion of insulin was initiated according to the following protocol: less than $9.99 \mathrm{mmol} / \mathrm{L}(180 \mathrm{mg} / \mathrm{dL}), 0 \mathrm{U} / \mathrm{h} ; 9.99$ to 12.21 $\mathrm{mmol} / \mathrm{L}(180-220 \mathrm{mg} / \mathrm{dL}), 1 \mathrm{U} / \mathrm{h} ; 12.27$ to $13.82 \mathrm{mmol} / \mathrm{L}(221-$ $249 \mathrm{mg} / \mathrm{dL}), 2 \mathrm{U} / \mathrm{h}$; and greater than $13.82 \mathrm{mmol} / \mathrm{L}$ (249 mg/dl), 3 U/h. Subsequently, blood glucose concentrations were measured every 30 minutes, and the insulin infusion rate was titrated according to the following protocol: less than $7.77 \mathrm{mmol} / \mathrm{L}(140 \mathrm{mg} / \mathrm{dL})$. Rate of infusion was maintained at 0 until $9.99 \mathrm{mmol} / \mathrm{L}(180$ $\mathrm{mg} / \mathrm{dL}$ ). Then the insulin infusion was restarted at a $50 \%$ rate of the previous infusion: 7.77 to $9.93 \mathrm{mmol} / \mathrm{L}(140-179 \mathrm{mg} / \mathrm{dL}$; decrease the rate by $0.5 \mathrm{U} / \mathrm{h}) ; 9.99$ to $12.21 \mathrm{mmol} / \mathrm{L}(180-220$ $\mathrm{mg} / \mathrm{dL}$; no change in the infusion rate); 12.27 to $13.82 \mathrm{mmol} / \mathrm{L}$ (221-249 mg/dL; if the blood glucose concentration was less than in the last test, the rate of infusion was unchanged, and if the blood glucose concentration was greater than in the last test, the infusion rate was increased by $0.5 \mathrm{U} / \mathrm{h}) ; 13.88 \mathrm{mmol} / \mathrm{L}$ or greater $(250$ $\mathrm{mg} / \mathrm{dL}$; the rate of infusion was increased by $1 \mathrm{U} / \mathrm{h}$ ). If the blood glucose concentration did not decrease after 3 successive measures, the insulin infusion rate was doubled. 